HID 44 (2017)

\title{
GANADERÍA Y FISCALIDAD SEÑORIAL EN LA BANDA MORISCA: LOS PRIMEROS CONDES DE UREÑA Y EL PADRÓN DE LAS YERBAS DE MORÓN DE LA FRONTERA $(1532)^{1}$
}

\author{
LIVESTOCK FARMING AND FEUDAL TAXATION IN THE BANDA \\ MORISCA: THE FIRST COUNTS OF UREÑA AND THE GRASS \\ CENSUS IN MORÓN DE LA FRONTERA (1532)
}

\author{
José María Martín Humanes \\ Max Planck Institute for European Legal History \\ humanes@rg.mpg.de
}

RESUMEN: Desde época bajomedieval la ganadería fue la principal fuente de riqueza de las comarcas sevillanas limítrofes con el reino nazarí de Granada. En territorios fronterizos como la Banda Morisca su impronta quedó fuertemente marcada en su poblamiento, perviviendo hasta bien entrada la modernidad. De su relevancia en estos espacios rurales dan buena cuenta documentos como el que presentamos a continuación, un interesante repartimiento ganadero elaborado para la villa de Morón de la Frontera en 1532 y conocido como el padrón de las yerbas. La pieza, inédita y única conservada para esta localidad, buscaba determinar la contribución que cada uno de sus vecinos debía realizar a la renta anual impuesta por los condes de Ureña a cuenta del uso y disfrute de sus baldíos. Ante la escasez generalizada de pastos, el pago de la misma mejoró sensiblemente la hasta entonces difícil situación de los ganaderos locales, gravemente afectados por la presencia de grandes cabañas foráneas y el creciente dinamismo de las actividades agrícolas.

PALABRAS CLAVE: Banda Morisca; ganadería; fiscalidad señorial; condes de Ureña; Morón de la Frontera; padrón de las "yerbas".

ABSTRACT: From late medieval times, livestock breeding was the main source of wealth for the population of the kingdom of Seville that lived in the areas bordering the Muslim kingdom of Granada, known as the Banda Morisca, and it continued to be so up to Modern times. The importance of livestock farming is reflected in the document under study in this article, where we are given an

1. Este trabajo se inserta dentro de las líneas de publicación del grupo de investigación HUM214 El reino de Sevilla en la Baja Edad Media, dirigido por la doctora Borrero Fernández y financiado por la Consejería de Innovación, Ciencia y Empresa de la Junta de Andalucía.

Abreviaturas utilizadas: AGS $=$ Archivo General de Simancas; $\mathrm{AMM}=$ Archivo Municipal de Morón de la Frontera; ARCHGR = Archivo de la Real Chancillería de Granada. 
account of how farming was organised in the town of Morón de la Frontera in 1532, using a system known as the Grass Census. The document reflects the rent paid by each farmer for the right of pasture in the uncultivated lands of the Téllez Girón family, Counts of Ureña. With a widespread shortage of pasture land, this system greatly improved the income of local livestock farmers, who had been seriously affected by the presence of large non-local herds and the everincreasing growth of arable farming.

KeYwords: Banda Morisca; livestock farming; feudal taxation; Counts of Ureña; Morón de la Frontera; Grass Census.

Desde época bajomedieval la ganadería fue la principal fuente de riqueza de las comarcas sevillanas limítrofes con el reino nazarí de Granada. En territorios fronterizos como la Banda Morisca su impronta quedó fuertemente marcada en su poblamiento, perviviendo hasta bien entrada la modernidad. De su relevancia en estos espacios rurales dan buena cuenta documentos como el que presentamos a continuación, un interesante repartimiento ganadero elaborado para la villa de Morón de la Frontera en 1532 y que sus contemporáneos conocían como el padrón de las yerbas. La pieza, inédita y única conservada para esta localidad, buscaba determinar la contribución que cada uno de sus vecinos debía realizar a la renta anual impuesta por los condes de Ureña a cuenta del uso y disfrute de sus baldíos. Ante la escasez generalizada de pastos, el pago de la misma mejoró sensiblemente la difícil situación de los ganaderos locales, gravemente afectados por la presencia de grandes cabañas foráneas y el creciente dinamismo de las actividades agrícolas.

La publicación de este documento supone, sin duda, un interesante aporte a la escasa nómina de fuentes ganaderas existentes para el Reino de Sevilla. Su principal atractivo radica en la posibilidad que nos brinda de sumergimos directamente en el mundo rural sevillano y acceder a valiosas informaciones socio-económicas sobre su vecindario, sus particularidades comarcales y las problemáticas que afectaban por entonces a los principales sectores productivos de la región. Nuevos materiales, en definitiva, que esperamos enriquezcan el debate y contribuyan a dotar de mayor solidez a nuestros conocimientos sobre la sociedad rural hispalense y andaluza.

A modo de sumario, éstos serán las cuestiones que trataremos a lo largo de las próximas páginas: en primer lugar, nos aproximaremos a la situación general de la ganadería en las tierras meridionales del Antiguo Reino de Sevilla, focalizando muy especialmente sobre la Banda Morisca y sus comarcas naturales de la campiña y la serranía sur. Acto seguido, nos detendremos en la identidad ganadera que caracterizó a la villa de Morón de la Frontera en el tránsito del medievo a la modernidad, y en la problemática que encerró la escasez de pastos que durante décadas padecieron los ganaderos de estas localidades. Del mismo modo, analizaremos la conocida capitulación de las yerbas de 1519, un acuerdo alcanzado entre la Casa de Osuna y los concejos de Morón y Arahal que terminó desbloqueando 
esta complicada situación. Ya en último término, el artículo recoge la transcripción íntegra de la pieza. Dada su extensión, daremos cuenta detallada de su contenido en una próxima aportación a esta publicación.

\section{LA GANADERÍA EN LAS TIERRAS MERIDIONALES DEL ANTIGUO REINO DE SEVILLA}

Del conjunto de vicarías que formaban parte del Arzobispado de Sevilla -vicaría de Sevilla, de Sanlúcar la Mayor, Aznalcázar y Tejada, de Niebla, Almonaster, Zufre y Constantina, de Carmona, de Écija, de Jerez, Sanlúcar de Barrameda, Rota, Puerto de Santa María, de Arcos de Moguer, Gibraleón y Huelva y el Obispado de Cádiz-, la Vicaría de Sevilla era la que acumulaba mayor volumen de ganado. Esta circunstancia se debía fundamentalmente a dos factores: por un lado, a la amplia extensión territorial de su circunscripción, que comprendía la de la propia ciudad de Sevilla más un elevado número de poblaciones circundantes, y por otro, al hecho de contar, al sur, con una de las zonas de mayor acento ganadero de toda la región, la rica comarca de la campiña.

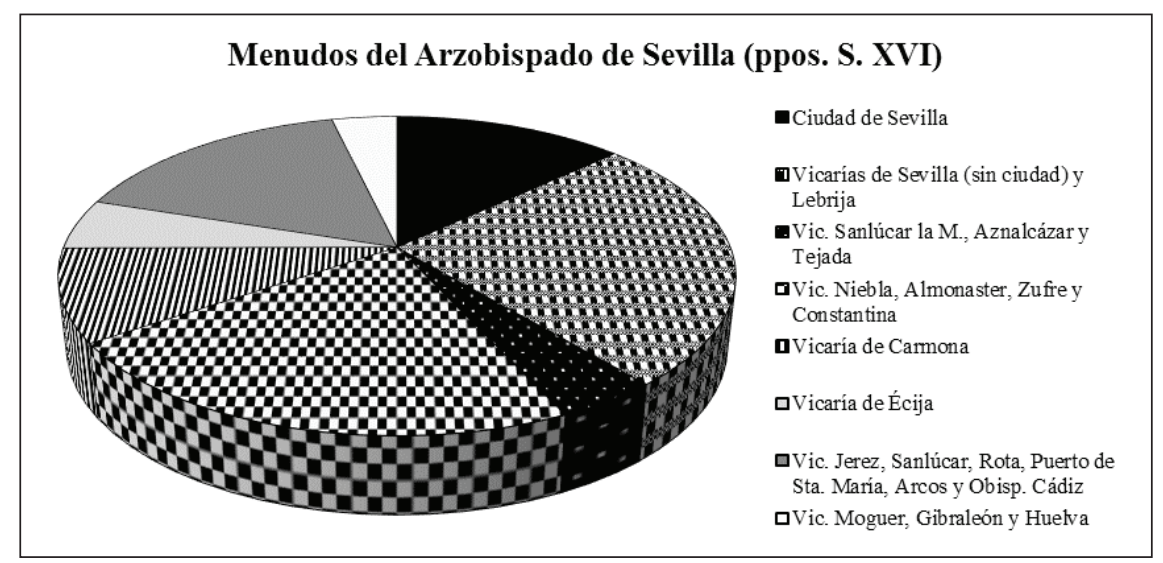

Ilustración no ${ }^{\circ}$. Menudos del Arzobispado de Sevilla (ppos. s. XVI). Cifras: Carmona Ruiz, M.A., La ganadería en el Reino de Sevilla durante la Baja Edad Media. Sevilla, 1995.

Son conocidos los avatares históricos que rodearon al sector meridional del antiguo Reino de Sevilla ${ }^{2}$. La amenaza de las razzias musulmanas derivada de la proximidad de la frontera con el reino nazarí de Granada, unido a situaciones como la debilidad demográfica de la región o la especial orografía de su territorio, hicieron inviable la actividad agrícola en la zona y que aquellos parajes silvestres, de montes, dehesas y tierras incultas, terminaran siendo aprovechados

2. González Jiménez 1996, 1987; González Jiménez, García Fernández 1992; García Fernández 2005. 
para la crianza de ganado. Dada la capacidad de adaptación a este contexto y su versatilidad, los animales se convirtieron muy pronto en pieza clave de su identidad y principal exponente de su riqueza ${ }^{3}$. Poblaciones sevillanas como Alcalá de Guadaira, Carmona, Écija, Marchena, etc. u otras tantas como Utrera, Lebrija, Jerez o Arcos, arrojaban a inicios de s. XVI unas cuantías elevadas en concepto de menudos recaudados por el Cabildo Catedral de Sevilla, señal inequívoca de los altos niveles de actividad y concentración de animales en este área ${ }^{4}$.

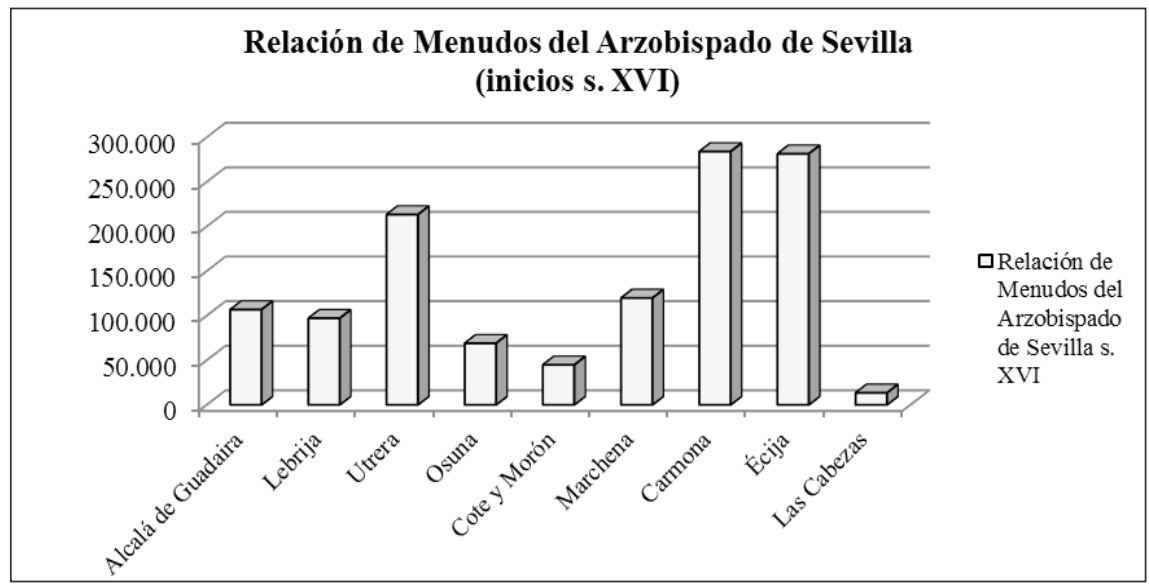

\begin{tabular}{|c|c|c|c|c|c|c|c|c|c|}
\hline \multicolumn{10}{|c|}{ MENUDOS RECAUDADOS EN EL AÑO DE 1520 } \\
\hline & $\begin{array}{l}\text { Alcalá de } \\
\text { Guadaira }\end{array}$ & Lebrija & Utrera & Osuna & $\begin{array}{c}\text { Cote y } \\
\text { Morón }\end{array}$ & Marchena & Carmona & Écija & $\begin{array}{c}\text { Las } \\
\text { Cabeza }\end{array}$ \\
\hline ( mrs) & 106.768 & 97.050 & 213.333 & 69.000 & 44.799 & 119.770 & 284.000 & 281.500 & 13.370 \\
\hline
\end{tabular}

Ilustración $n^{\circ}$ 2. Relación de menudos del Arzobispado de Sevilla (inicios s. XVI). Cifras: Carmona Ruiz, M.A., La ganadería en el Reino de Sevilla durante la Baja Edad Media. Sevilla, 1995.

A ellas debemos sumar también las cifras que exhibía la propia ciudad de Sevilla, donde estaban radicados los principales propietarios de ganado del sur peninsular y cuyos problemas espaciales, provocados fundamentalmente por lo reducido del alfoz sevillano, les hicieron optar de manera mayoritaria por desplazar sus cabañas hacia las cercanas comarcas sureñas, donde las tierras de la Banda Morisca desplegaban todo su atractivo.

3. Carmona Ruiz 1995, 1996. Sobre el papel de la ganadería en el sur peninsular, véanse también Argente del Castillo Ocaña 1991; Devís Márquez 1997; Cabrera Muñoz 2002; Martín Gutiérrez 2015. Otros aportes interés para el marco peninsular, Clemente Ramos 2001; Monsalvo Antón 2010.

4. Carmona Ruíz 2009; 1997a; 2001; 2014. 


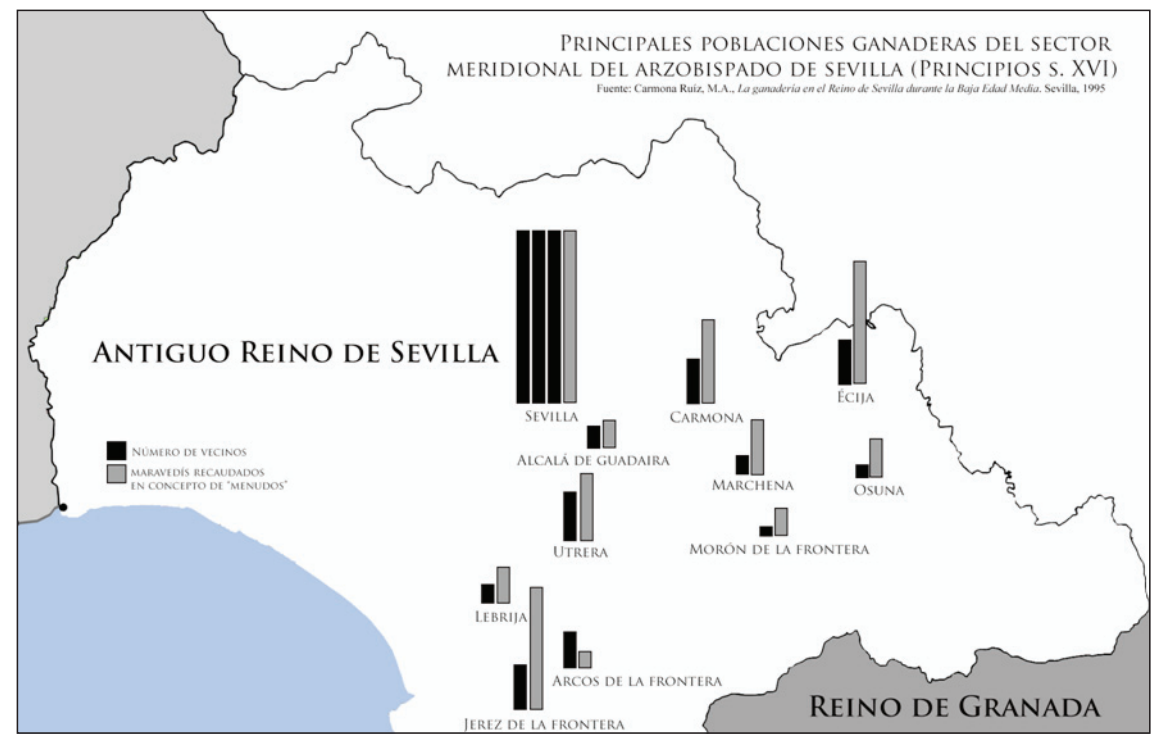

Ilustración $n^{0} 3$. Principales poblaciones ganaderas del sector meridional del Arzobispado de Sevilla.

Inserta en esta antigua marca territorial, la villa de Morón de la Frontera jugó un papel destacado dentro de este escenario económico. Diferentes documentos de la época ponen de manifiesto que el canpo moronense soportó una elevada presión ganadera como consecuencia del traslado de grandes cantidades de animales a los que su paisaje ofrecía extraordinarias condiciones para su crianza y reproducción. Su cercanía a la primera línea de frontera había provocado que se respetaran sus principales reservas naturales, sobre todo en las primeras estribaciones de la subbética, donde la escarpada serranía contribuía a conservar extensas dehesas ricas en aguas y pastos. Su perfil demográfico invitaba también a la adopción de este tipo de medidas, pues su vecindario, de escasa entidad, no disponía por sí mismo de la capacidad suficiente para la roturación y puesta en explotación de aquellas tierras. A todo ello debemos sumar, además, que por parte de los señores del lugar existía la antigua costumbre de permitir la entrada en su territorio de cabañas foráneas como fórmula para obtener importantes réditos económicos ${ }^{5}$. De hecho, ya en tiempos de los maestres alcantareños matas señoriales como las del maestre se entregaban al mejor postor, estando durante décadas en manos de los grandes ganaderos de la región.

5. Como consecuencia de la escasez de pastos en sus respectivas localidades, muchos ganaderos de estas comarcas se vieron obligados a buscar otras alternativas. AGS, CCA, DIV, 43, 34. Declaraciones de testigos, sobre los pastos del Campo de Matrera y su arrendamiento por la ciudad de Sevilla a vecinos de Coronil, Utrera, Los Morales, Arahal, etc., y pago de derechos para guardería y acostamiento. Véase también Villalonga Serrano 2007. Véase también un interesante aporte para fuera de nuestras fronteras, Andreolli 2001-2002. 
El cambio jurisdiccional que tendría lugar en Morón de la Frontera durante la segunda mitad del s. XV no interrumpiría este proceder en la explotación económica de buena parte del alfoz local, antes al contrario; los Téllez Girón, apremiados por las urgencias de su hacienda condal y con la voluntad de rentabilizar al máximo la extensión territorial de sus dominios, potenciarían estos acuerdos al menos hasta el año de 1519, fecha en la que se firmaría la capitulación de las yerbas entre la Casa de Osuna y los concejos de Morón y Arahal, produciéndose un giro de ciento ochenta grados en esta política económica que pondría fin a la presencia de ganado foráneo en la zona.

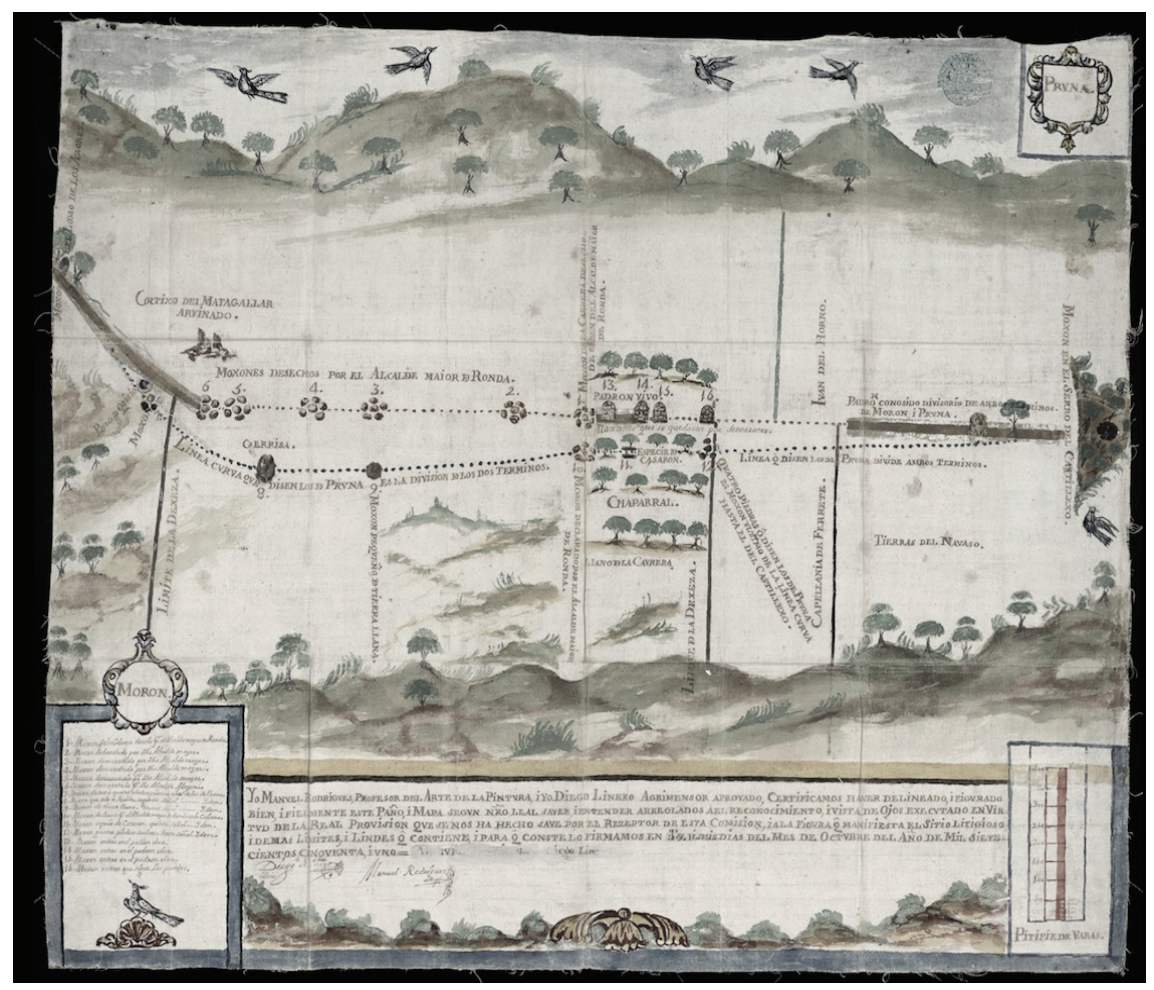

Ilustración $n^{\circ} 4$. Paisajes de la Banda Morisca. Paño y mapa hecho a vista de ojos del límite entre los términos de los pueblos de Pruna y Morón de la Frontera (s. XVIII). Archivo de la Real Chancillería de Granada. Signatura: ES.18087.ARCHGR/059CDFI/MPD nº 70.

\section{LOS CONDES DE UREÑA Y LA CAPITULACIÓN DE LAS YERBAS DE 1519}

Han sido los testimonios localizados en el Archivo de la Real Chancillería de Granada referentes a la capitulación de las yerbas los que nos han informado con detalle sobre la situación de escasez de pastos que sufrían los locales, los perjui- 
cios que el arrendamiento a extranjeros había estado ocasionando durante décadas al desarrollo económico de la comarca y los pormenores contractuales que daban forma al referido acuerdo ${ }^{6}$. Más concretamente, la mayoría de los datos han sido aportados por las probanzas de un pleito de la desmería de términos que ambas poblaciones mantuvieron en los tribunales reales granadinos a mediados de siglo XVI, donde aparece reflejado el jugoso y extenso testimonio del escribano público del Arahal Alonso Guisado, escribano de la villa de Sevilla (que) bibió mucho tiempo en la villa del Arahal y fue escrivano público e del crimen, cuentas y de las tutelas de la dicha villa muchos años?.

La capitulación firmada entre la Casa de Osuna y sus concejos de Morón de la Frontera y Arahal en el año de 1519 tuvo desde sus primeros momentos un claro trasfondo económico, no logrando concretarse hasta que ambas poblaciones no fueron capaces de plantear una oferta económicamente superior a la que por entonces percibía el conde de sus arrendadores foráneos. De hecho, fueron estos réditos económicos unidos a los posibles beneficios futuros derivados de la presión impositiva sobre sus vasallos, los que terminarían provocando que Juan Téllez Girón, el conde viejo, decantara la balanza en favor de los locales.

Según el relato de Guisado, a finales de la década de 1510 una delegación de los concejos de Morón y Arahal se reunió con los administradores del segundo conde de Ureña para solicitar la concesión de la merced del campo e término del señorío de Morón, propiedad de la Casa de Osuna y por entonces arrendada a extranjeros $^{8}$. Aunque estos acuerdos representaban una importante fuente de in-

6. Véase el documento ARCHGR, caja 1377, pieza 6. Pleito entre el concejo de la villa de Arahal con el de la villa de Morón, sobre términos. Asimismo, nos ha resultado de utilidad el expediente ARCHGR, caja 1375, pieza 14, descrito como Probanza del concejo de la villa de Arahal con el concejo de la villa de Morón, sobre términos. En origen este segundo documento formaba parte del primero, si bien en el catálogo del archivo granadino ambas piezas aparecían clasificadas como dos entradas distintas. En el momento de la elaboración de este artículo esta segunda pieza aún constituía una unidad documental independiente. En adelante, la dirección del Archivo de la Real Chancillería de Granada ha estimado recuperar la unidad original y volcar su contenido en el expediente ARCHGR, caja 1377 , pieza 6 .

7. ARCHGR, caja 1377 , pieza 6 , ff. $2 \mathrm{v}-3 \mathrm{r}$.

8. La renta de la "yerba" le fue concedida a Morón por la orden de Alcántara en febrero de 1452, junto a la renta de la leña y las matas de Raygalobos, Gutyer Ruyz y de Alcotera, habida cuenta de "los grandes gastos e trabajos en la dicha nuestra villa e vezinos della tienen por causa de la guerra continua de los moros enemigos de la nuestra fee”. AMM, Patrimonio, leg. 1084, f. 459r. (1452.2.23). Carta de donación a la villa de las matas, con su leña y hierba, por parte del maestre de Alcántara. "Nos don Gutierre de Sotomayor, maestre de la cavallería e horden de Alcántara, señor de las villas de Gaete e Finojosa e Alconchel e la Puebla de Alcozer, por quanto entre los arrendadores de las rentas de la nuestra villa de Morón de la Frontera e el conçejo alcal- // ${ }_{459 \mathrm{v}}$ des alguazil e regidores, jurados e omes buenos de la dicha nuestra villa de Morón de la Frontera, a seydo y es çierto debate e contienda sobre raçón de la leña e yerva de las matas de Raygalobos e de Guter Ruyz e de Alcotera, propios del dicho conçejo, lo qual todo nos mandamos ver a letrados e se falló la dicha leña e yerba de las dichas matas perteneçer a nuestra horden e a los dichos nuestros arrendadores en nuestro nonbre, e agora nos aviendo respeto a los grandes gastos e trabajos en la dicha nuestra villa e vezinos della tienen por causa de la guerra continua de los moros, $/{ }_{460 \mathrm{r}}$ enemygos de la nuestra fee, por la presente fazemos merçed al dicho conçejo alcaldes alguazil regidores jurados e omes buenos de la dicha nuestra villa de Morón de la dicha leña e yerva de las dichas matas de Raygalobos e de Guter Ruyz e de Alcotera, para que 
gresos para la señoría, la consiguiente reducción de los espacios ganaderos estaba perjudicando gravemente a la cabaña local, impidiendo el pasto de las reses y su libre tránsito. No en vano, ya en 1501 estos mismos problemas obligaron a la firma de acuerdos entre los concejos vecinos para permitir el aprovechamiento de sus tierras comunales ${ }^{9}$.

Las gestiones realizadas por los concejos de ambas localidades llegaron pronto a buen puerto, plasmándose el acuerdo en la célebre capitulación de las yerbas, la cual establecía las siguientes condiciones:

1. A partir de 1519 , fecha de la firma, Juan Téllez Girón suspendía sus arriendos a terceros y se comprometía a ceder a los concejos de Morón y El Arahal las dehesas de las que éste disponía en ambas localidades, a fin de que en ellas pastasen y transitasen únicamente los ganados de sus vecinos y vasallos.

2. A cambio, se acordaba el pago por parte de los concejos de Morón y Arahal de una renta anual de 50.000 maravedís a sufragar de manera conjunta, la cual debía hacerse efectiva cada año por el día de San Miguel.

3. Por la parte del conde se concedía, además, licencia a ambos concejos para poder nombrar a cuatro mayordomos del campo, dos por cada población, para que llevasen conjuntamente la guarda e custodia del campo en sus respectivos términos, y que en caso de infracción la sanción económica recaudada fuera a parar a las arcas de la hacienda municipal donde se hubiera cometido el delito, contribuyendo de esta forma a sufragar las cuantías fijadas en el contrato ${ }^{10}$.

las ayan e tengan e posean e gozen dellas e de la renta dellas ellos o quyen ellos quysieren o su poder ubieren agora e de aquy adelante, en tal manera que las dichas matas de Raygalobos e de Guter Ruyz e de Alcotera sean libres e esentas e del dicho conçejo enteramente e gozen dellas como de propios del dicho conçejo para // ${ }_{460 \mathrm{v}}$ sus necesidades. E las otras cosas que a nuestro serviçio e bien e guarda de la dicha nuestra villa cumpliere e menester fuere, mandamos que ningund arrendador ny mayordomo de la dicha nuestra horden ny otra persona alguna no se entrometa a lo demandar ny perturbar de aquy adelante so pena de la nuestra merçed e de diez myle maravedís para la nuestra cámara (...)".

9. A tenor de estos nuevos acuerdos, intuimos, pues, que la hermandad de pastos firmada en 1501 por las poblaciones vecinas de Marchena, Morón, El Arahal y Puebla de Cazalla no debió resultar demasiado efectiva. Carmona Ruíz, 1997b.

10. ARCHGR, caja 1377, pieza 6, ff. 9v-10v. "Yten si saben que tan bien asimismo de conformidad e acuerdo de los conçejos de ambas las dichas partes villas estaban asentadas fechas e capituladas las cosas contenidas en la capitulación que dizen de la yerva de que está fecha demostración por parte del conçejo de la villa del Arahal antel receptor para que lo lea e muestre a los testigos que como parece por ella pidieron de merçed al conde don Juan señor de las dichas dos villas abuelo del duque don Pedro Girón que oy es señor dellas que les diese el // $10 \mathrm{r}$ dicho canpo e término çerrado para que por arrendamiento ny en otra manera no entrase en él otro ganado sino el de los vezinos dellas por preçio de çinquenta myle maravedis que le pidieron por merçed que tuviese por bien que se los pagasen juntos en una paga por el día de San Myguel de cada año y que se repartiesen e pagasen entre los vezinos por la manera que se dize en la dicha capitulaciçión e le hizo merçed de dar lysençia para que cada uno de los dichos conçejos pusiese dos mayordomos el concejo del Arahal dos e el otro dos el conçejo de Morón para la guarda del dicho canpo e yerva que lo guardasen juntos con las que él tenía y que las penas que tomasen los mayordomos del Arahal fuesen para el conçejo del Arahal y si se acertasen a hallar juntos alpeñar (sic) las partiesen por medio y cada mayordomo acuda con ellas a su conçejo para ayuda a pagar los dichos cinquenta myle maravedis de la dicha yerva e conforme 
La cuota que correspondió pagar a ambos concejos nunca fue equitativa. Ya desde sus inicios y dadas las numerosas cabezas de ganado con las que contaba la cabaña arahalense, la aldea se vio obligada a abonar cantidades por encima de los 30.000 maravedís, quedando los 20.000 restantes asignados a Morón ${ }^{11}$. El propio Guisado afirmaba en su declaración conocer con detalle la gestión burocrática del acuerdo, al haber sido durante años escribano del cabildo del Arahal y haber

"visto la dicha capitulación de la yerva (...) en el archibo del cabildo de la dicha villa del Arahal siendo escrivano del cabildo (e) leyó muchas vezes e sacó e dio dellas traslados autoriçados para los negocios e cosas en que heran necesario presentarse".

Asimismo, aporta datos muy interesantes sobre el procedimiento de cobro de estas cantidades, pues

"las cuantías se pagaban a los mayordomos y recaudadores del dicho conde y lo sabe porque como escribano de la villa del Arahal redactaba las libranzas y cartas de pago a los mayordomos que emitía después el concejo de la villa del Arahal, realizado este trámite cada final de año y lo sacaba de sus propios e rentas que avian cobrado (...) e porque posteriormente (...) sería mayordomo e recaudador de la dicha villa por el dicho Duque don Pedro Girón conde de Ureña que oy vive, y cobró al concejo los 30.000 maravedis (...)".

Respecto a la confección del padrón, Guisado añade que

"en cada año de los queste testigo tiene dicho que fue escrivano del dicho cabildo hazía padrón en el tienpo del agosto de los vezinos que tenyan ganados, los quales con juramento ante este testigo como tal escrivano del cabildo declaraban el ganado que cada uno tenía (...) e el concejo nonbrava una persona para que juntase los dichos maravedis que montava la dicha copia y ansi desta manera se cobravan e pagavan los dichos condes ${ }^{12}$ ".

La vigencia de esta capitulación, al menos en el caso de Morón, se mantendría hasta los años de gobierno de su hijo Juan Téllez Girón, cuarto conde de Ureña - de ahí que el padrón sea uno de los últimos repartimientos que se redactaran con este

a esto se hizo repartimyento de lo que cada una de las dichas villas avía de pagar y contribuir y a la villa y conçejo de Morón le cupo a pagar veynte myle maravedís por tener menos ganado y al conçejo e villa del Arahal treynta myle maravedís por tener más número de ganado y el conçejo de Morón pagó sus veynte myle maravedís siempre hasta $/{ }_{10 \mathrm{v}}$ que el conde don Juan hijo del conde don Juan uvo por bien y les hizo merçed de soltárselos en pago e remuneración de otros servicios que le hizieron y el conçejo del Arahal los a pagado e paga hasta oy y ansi se a fecho usado e guardado e los testigos lo an visto ser e pasar ansí en sus tienpos e an oydo decir a sus mayores e más ancianos que ansí pasó en los suyos y tal a sido y es pública voz e fama y común opinión e si otra cosa fuera e pasara los testigos lo supieran y no pudieran ser menos".

11. ARCHGR, caja 1377 , pieza 6, f. $12 \mathrm{v}$.

12. ARCHGR, caja 1377 , pieza 6, f. $12 \mathrm{v}$. 
propósito en esta localidad-, quien suprimiría la tasa que asumía el concejo a cambio de ciertos acuerdos en los pleitos que la Casa mantenía con los particulares $^{13}$.

Tenemos pocos datos que nos permitan constatar si este nuevo régimen de explotación de las fincas señoriales provocó verdaderamente un incremento importante del volumen de la cabaña ganadera local. Parece lógico pensar, y así debieron entenderlo los principales ganaderos moronenses, que las mejoras de las condiciones generales de sus cabañas iban a terminar favoreciendo a corto-medio plazo la situación de su hacienda y, por ende, la de su patrimonio, de ahí que se erigieran como los grandes promotores políticos y económicos de los acuerdos. Desgraciadamente, no tenemos datos a este respecto. Las únicas cifras que muestra el padrón reflejan que en 1532 la villa de Morón de la Frontera presentaba un total de 18.700 cabezas de ganado, lo que se traducía en algo más de 5.300 unidades ganaderas, y que su aldea del Arahal contaba con algo más de 7.900 ug., haciendo que el señorío dispusiera de un total cercano al de las 13.000 unidades ganaderas ${ }^{14}$. Las llamativas diferencias que se aprecian entre el coeficiente fiscal de ambas poblaciones debieron originarse mucho antes de la data, sobre todo a cuenta de la situación aventajada que históricamente había disfrutado el vecindario arahalense respecto al de Morón, resultantes de su posición en la retaguardia fronteriza, y de la influencia que ejercía sobre la misma su ubicación sobre una de las principales vías de comunicación del sur peninsular ${ }^{15}$.

13. ARCHGR, caja 1377, pieza 6, f. 13v. Así lo confirma el propio Guisado al declarar que "este testigo a visto e leydo algunas vezes una capitulación y concordia confirmada por el emperador don Carlos nuestro señor ques en gloria la qual se refirió e pasó e se hizo entre el dicho don Juan Téllez Girón conde de Ureña difunto padre del dicho don Pedro Girón conde de Ureña que oy es e los vecinos particulares de la dicha villa de Morón y sobre çiertos pleytos que trayan con el dicho conde y entre otras cosas quel dicho conde les dio en la dicha capitulación e concordia les soltó los dichos veynte mile maravedís que pagavan por la yerva para que desde en adelante no la pagasen y asi sabe este testigo y es cosa muy notoria que nunca más se la pagaron después aca por esta causa e que a hombres viejos e antiguos de las dichas villas este testigo oyó dezir que lo susodicho se hizo e guardó siempre".

14. La unidad ganadera es un índice fiscal equivalente a una cabeza de ganado de referencia. Se emplea desde época bajomedieval para poder realizar análisis comparativos globales de las cabañas ganaderas. En nuestro caso, sabemos con detalle cómo se llevaba a cabo la conversión a unidades ganaderas de las distintas cabañas locales gracias a la descripción realizada por el propio Alonso Guisado, que relata el procedimiento de esta manera: “(...) y fecho el padrón este lo sumava el ganado que avía haziéndolo todo número de cabezas de vacas conforme a la dicha capitulación de tal manera que dos bueyes se contavan e contavan por una vaca e una yegua por una vaca e diez ovejas e diez cabras e diez carneros e diez corderos e diez puercos por una vaca cada diez e cada vaca por vaca e visto el número y copia que se hazía de vacas les repartía a cada cabeza de vaca lo que le cabía para ensir el número de los treynta mile maravedís entre ellas e dello hazía un padrón de las personas y las vacas que cada uno tenía y montavan sus ganados por este horden que tiene dicho y hazía copia e padrón (...)”. ARCHGR, caja 1377, pieza 6, f. 13v.

15. García Fernández 2011; Martín Humanes 2015. Sobre las actividades ganaderas, véase también Carmona Ruíz 2000a, 2000b, 2011. 


\section{El RePartimiento o PADRón DE LAS YeRBAS}

El documento que presentamos a continuación es el repartimiento o padrón de las yerbas. Conocido así por sus contemporáneos, constituye un instrumento clave para conocer con todo lujo de detalles la fisonomía de la ganadería moronense a inicios de s. XVI. Fechado el 24 de Junio de 1532, se trata del único padrón conservado de los que se confeccionaban anualmente en Morón de la Frontera por el día de San Juan con el propósito de distribuir entre todos los vecinos el coste asumido del arrendamiento, uso y disfrute de los baldíos que los condes de Ureña tenían en Morón y en la pedanía del Arahal ${ }^{16}$. La pieza, inédita hasta la fecha, se puede consultar en el Archivo Municipal de Morón de la Frontera, dentro de la sección Justicia/Pleitos, e inserto en el legajo 832, fol. 399r.

Una de las características más interesantes de este repartimiento es que a diferencia de la amplia mayoría de los de su categoría, dispone de un altísimo grado de representatividad; de hecho, recoge a todos y cada uno de los vecinos de Morón, a los que acompaña del ganado que tenían en propiedad ${ }^{17}$. En efecto, aunque no es nada habitual, en el documento aparece registrado y cuantificado todo el vecindario incluidos pecheros, caballeros cuantiosos, privilegiados y hasta eclesiásticos, a los que se acompaña, al margen, del número de reses y su coeficiente en unidades ganaderas. Nada sabemos sobre el patrimonio de conventos, monasterios y pequeños santuarios locales, posiblemente exentos, si bien llegan a incluirse distintas personalidades muy próximas a los Téllez Girón, que en unos casos ejercían como delegados locales de la Casa de Osuna y en otros ostentaban altos cargos ejecutivos de su administración.

En lo que respecta a la posibilidad de fraude en las declaraciones o en la confección del propio padrón, debe aclararse que al tratarse de un instrumento fiscal realizado por las autoridades municipales en donde la carga, ya acordada de inicio, iba a recaer plena e inexorablemente sobre el conjunto del vecindario, las posibilidades de opacidad, manipulación y amaño debieron ser mucho menores que de costumbre, aumentando así su grado de verosimilitud respecto a otros padrones ${ }^{18}$.

No obstante, no todo han sido ventajas a la hora de trabajar con esta pieza. De entrada, supone un importante contratiempo que se trate de una fuente local con unas características y un contexto tan específicos, pues ello dificulta su utilización

16. AMM, Justicia, pleitos, leg. 832, fol. 399r.

17. Carmona Ruíz 1995, pp. 493-494. “Otra cuestión es saber si en los padrones figuran todos los vecinos de una localidad. Aunque en su confección se establecía la obligatoriedad de incluir en ellos a todos los vecinos, aunque fueran francos, exentos, familiares o bacinadores, sin embargo, no siempre aparecen todos los "privilegiados" y cuando lo hacen, normalmente no se contabiliza su hacienda. En resumen, en los padrones fiscales, al ser su finalidad exclusivamente tributaria, no aparecen aquéllos grupos exentos de pago, es decir, el elemento eclesiástico, así como los grupos privilegiados. Otra dificultad que nos plantea este tipo de fuente es el de la existencia de fraudes fiscales, aunque las propias características de estos padrones y el control establecido sobre los vecinos hicieron dificil que éstos se produjeran, rectificándose en las ocasiones que se descubrieron".

18. En este tipo de repartimientos el fraude fiscal terminaba repercutiendo en lo pechado por el resto de los vecinos, de ahí lo inusual de las prácticas evasivas. 
en análisis comparados con otras tipologías de fuentes. Además de esta particularidad, el estudio evolutivo ha sido del todo imposible, pues por desgracia no se ha conservado el resto de repartimientos confeccionados en Morón desde 1519 hasta 1532, lo que nos hubiera permitido conocer cómo fue transformándose la cabaña local durante estas décadas. Igual suerte corrieron los de la aldea vecina del Arahal.

También nos ha llamado poderosamente la atención cómo el repartimiento no contempla en ninguna de sus variantes el ganado híbrido, es decir, ni mulas ni asnos aparecen recogidos ni contabilizados en el padrón. Posiblemente esta ausencia pueda deberse a que en muchos de estos lugares ciertos animales estaban exentos de tributación, dado lo extendido que se encontraban ${ }^{19}$. Una situación muy similar encontramos con el ganado bravo y caballar, también muy presentes en esta región pero que tampoco aparecen reflejado plenamente en el padrón. Todos los ejemplares contabilizados en el repartimiento fueron yeguas, una circunstancia que atribuimos a la importancia que el caballo alcanzó en las zonas fronterizas, de tensión bélica constante, y que lo convertirían muy pronto en un bien libre de cargas. En el caso de los toros, además del atractivo del cuero y la carne, solían emplearse en la celebración de festividades locales, enlaces matrimoniales, bodas y nacimientos reales, conquistas de reinos, ciudades y otros eventos extraordinarios.

Otro de los escollos importantes que suscita el trabajar con este tipo de documentos, sobre todo cuando nos sumergimos de lleno en el mismo, es que muy a menudo las unidades ganaderas expuestas en los balances finales no terminan coincidiendo con las cuantías desglosadas en cada uno de los registros de los propietarios. En ocasiones, esta circunstancia puede atribuirse a errores en la confección del documento, aunque son las menos, pues lo habitual fue que la situación de las reses, bien por edad, estado de salud o taras físicas, terminara provocando que éstas fueran contabilizadas por debajo del coeficiente fiscal correspondiente. Por contra, también conocemos casos en los que las cifras que presentan los propietarios son superiores a las que en teoría le correspondería por la descripción realizada de su cabaña; y es que otras veces el desarrollo físico de las reses más jóvenes hizo que el contable las clasificara como categorías superiores dentro de la misma especie, haciéndolas tributar como tal. También se deben sumar dentro de este apartado aquellos casos de animales en proceso de gestación que por esta situación verían incrementada su valoración y, por ende, su tributación ${ }^{20}$.

19. El caso del ganado mular la ausencia parece deberse a motivos algo distintos, pues éste era poco numeroso en esta región, muy caro y los escasos ejemplares existentes quedaban reservados para tareas muy concretas que requerían de sus extraordinarias cualidades - potencia física para la tracción de molinos-. No obstante, sabemos que el ganado híbrido, por su valía para el transporte/acarreo de mercancías y para el conjunto de labores agrícolas cotidianas, debió representar un porcentaje considerable en el conjunto de la cabaña local que no aparece recogido en el padrón.

20. A lo largo de todo el texto son constantes las referencias explícitas a herales, novillos, puercos, etc., para así diferenciarlas de vacas, novillos y cochinos, siendo su tributación más reducida que la de las reses adultas. Carmona Ruíz 1995, p. 427. "En los padrones fiscales, las vacas utilizadas para la reproducción se dividen en tres, con un valor diferente. Así, las más caras eran las denominadas "vacas paridas", que eran las que en ese momento estaban criando, seguidas de las "vacas 


\section{TRANSCRIPCIÓN DEL DOCUMENTO}

1532, junio, 24. Morón de la Frontera.

El padrón de la renta de la "yerva".

AMM, Justicia, Pleitos, legajo 832, fol. 399r-415r.

$/{ }_{399 r}$ En la villa de Morón de la Frontera, lunes, día de Señor San Juan, beynte e quatro días del mes de junyo de mill e quinientos e treynta e dos años, en la plaça pública desta dicha villa, ante mí, dicha gente questava presente se pregonó por boz de Cristóval de Vaena, portero del concejo desta dicha villa, e por virtud de un hordenamiento de los señores oficiales del concejo desta dicha villa, que todas las personas, vecinos e moradores desta dicha villa, se vengan a contiar cada uno el ganado que tiene, para que así contiados se eche el repartimiento para que se pague a su señoría los cinquenta mill maravedís de la yerva que se paga en cada uno año, e que se vengan a cumplir dende oy dicha día hasta quinze días del mes de Julio primero que viene, donde no que se les echarán la quenta con el doblo.

Las quentas que cada un vecino desta dicha villa e otras personas que en ella tienen ganados hizieron son las siguientes:

Juan Fernández de las Casas

Juan Vázquez

Orejón

Hernando de Valbuena
El señor alcaide Juan Fernández de las Casas juró dos mile e quinientas cabeças de ganado ovejuno ochoçientos puercos XXXIIII bueyes seys vacas çinco yeguas montan todas trezientas e çinquenta e ocho vacas e veynte e çinco cabras e quatro bueyes que son quatro vacas y media.

El señor alcaide Juan Vázquez Orejón ciento e veynte e quatro vacas e diez e ocho bueyes e tres yeguas que son por todas çiento e treynta e seys vacas.

Hernando de Valbuena juró seys bueyes e dos yeguas son cinco vacas.

Aparicio Martín juró dos bueyes e una yegua.

Antón López yerno de Alonso de Palma juró un buey media vaca.

Alonso Fernández Villalón juró que tiene dos bueyes que es una vaca.

$/ /_{399 v}$ Diego Portillo juró diez bueyes e çinco vacas e dos yeguas e siete puercos son todos doze vacas y media.

La bivda de Pedro Mateos juró que tiene siete bueyes son tres vacas y media e siete vacas dos yeguas e veynte puercos son todas catorze vacas.

Cristóval Ramírez juró quatro vacas e VII bueyes e una yegua que son ocho vacas y media.

Francisco Gutiérrez juró siete vacas ocho bueyes son quatro bueyes vacas dos una yegua que son doze vacas.

Hernando de Avezilla juró quatro bueyes una yegua son tres vacas.

Los hijos de Juan Lobo juró doze vacas nueve bueyes quatro vacas y media quatro yeguas que son veynte vacas y media.

Andrés González de Orellana juró quatro vacas doze bueyes dos yeguas ciento e quinze cochinos cinquenta e cinco ovejas son veynte veynte e nueve vacas.
IIII L VIII

IIII m

I XXX VI

V

VIIIm

preñadas", en estado de gestación, siendo las más baratas las "vacas vacías", que eran las que no estaban preñadas ni criando". 
Calle Marina González la Molina
Calle del Bosque
Francisco Ximénez yerno de Bonilla juró ocho bueyes quatro vacas e seys vacas una yegua e dozientos e cinquenta puercos son XXV vacas son treynta e seys vacas.

\section{Juan Gutiérrez de Marehena}

Hernán González yerno de Alonso de Umanes juró dos bueyes e una vaca son dos vacas.

Su yerno el de Juan Sánchez tyene ocho bueyes y doze vacas que son.

Juana Sánchez madre de Pedro González tyene quatro bueyes y quatro yeguas y dos vacas que son VII vacas.

Su hijo tiene ocho bueyes e doze vacas que son.

$/ /{ }_{400 r}$ Francisco Sánchez Trugillo juró dozientas e veynte e çinco cabras e tres yeguas que son veynte e çinco vacas y media.

Marina González la Molina juró Miguel Sánchez Rabadán que tiene cinquenta e quatro vacas con diez herales y diez e siete bueyes que son VIII vacas y media más dos vacas que son LXIIII vacas y media.

Sancho García de Vargas juró tres bueyes que es una vaca y media.

Alonso Casado juró quatro bueyes dos vacas.

Alonso Fernández Serrano quatro bueyes e una vaca e una yegua son quatro vacas.

Bartolomé García Cabrero juró quatro bueyes dos vacas una yegua e dozientas cabras que son veynte e tres vacas.

Alonso de Umanes el viejo juró ocho bueyes treynta e una vacas tres yeguas son treynta y ocho vacas.

Garci González hijo de Juan de Osuna veynte e syete vacas siete bueyes dos yeguas más un novillo son XXXIII.

Diego Román juró quatro vacas e çinco bueyes dos vacas y media que son seys vacas y media.

Cristóval Romero juró quatro vacas dos bueyes una vaca una yegua son seys.

\section{Pedro Mateos el moȩo}

$/ /{ }_{400 v}$ Alonso Ximénez de Bejer juró que tiene dos bueyes que son una vaca.

Juan de Arenas juró dos bueyes e dos yeguas tres çinco vacas e sesenta e cinco cochinos que son catorze vacas e media.

Alonso Jiménez de Osuna juró dos bueyes que es una vaca e una yegua ciento e treynta cabras son todas quinze vacas.

Francisco Hortiz el viejo juró dos bueyes.

Antón Jiménez de Osuna el moço juró tres bueyes e dos vacas e ciento e veynte cabras son doze vacas e media que son quinze vacas y media.

Juan de Orellana el de Ronda juró dos bueyes e dos yeguas e sesenta cochinos que son todos nueve vacas.

Antón Jiménez de Osuna el viejo juró un buey y una yegua.

Miguel Martín Amo juró dos yeguas dos vacas.

Juan García Leal juró dos bueyes una vaca diez cabras una vaca son dos vacas.

Juan Fernández de Cote.
XXXVI

$$
\text { II }
$$

XVI

VII

XVI

XXVm

LXIIIIm

Im

II

IV

XXIII

XXXVIII

XXXIII

VIm

$\mathrm{XIVm}$ 
$/{ }_{401 r}$ Mari Blázquez que es bivda juró Antón Martín su hijo que tiene dos bueyes que son una vaca.

Alonso de Orellana juró quatro bueyes una yegua son tres vacas.

Hernán de Ontiveros juró tres bueyes e dos vacas dos yeguas quarenta cochinos son todas nueve vacas y media.

Diego Gil hijo de Martín Git

Juan de Orellana hijo de Alonso Ximénez de Osuna juró tres bueyes e una yegua dos vacas y media.

Juan Martín yerno de Miguel Sánchez juró dos bueyes una vaca.

Alonso Salvador juró una vaca.

Juan Despinal Vençón juró ocho bueyes quatro vacas.

Juan Đes Garçi Fernández hijo de Mari Fernández juró que tiene tres vacas e dos bueyes son cinco vacas.

Pedro Fernández (...) tres bueyes vaca y media una vaca una yegua tres vacas y media.

Antón Fernández Herrador juró quatro bueyes dos vacas una yegua setenta cabras que son todas diez vacas.

Calle Nueva Juan de Osuna juró LXXII vacas XVIII bueyes son nueve vacas quatro yeguas sesenta e çinco cochinos que son seys vacas y media son todas noventa e un vacas y media.

// ${ }_{401 v}$ Bartolomé Ruyz juró dos bueyes que es una vaca.

Toribio Fernández juró tres bueyes.

Andrés Notario el viejo juró veynte e nueve puercos son tres vacas.

Pedro Fernández Pastor juró una vaca siete bueyes una yegua e quarenta puercos son todos nueves vacas y media.

Juan Martín Bermejo juró quatro bueyes dos vacas tres vacas otros dos bueyes una vaca una yegua que son siete vacas.

Juan Florido juró una vaca e un buey.

Pedro García Campo juro siete bueyes es tres vacas y media seys vacas y una yegua e ȩiente sesenta cochinos que son seys vacas son todas diez e seys vacas y media.

Cristóval de Porras juró tres bueyes e una vaca e una yegua son tres vacas y media.

Martín Fernández Galvarro juro una vaca e tres bueyes que son dos vacas y media.

Juan Despinal Cabrero juro dos bueyes una vaca ciento e quarenta cabras que son quinze vacas.

Juan Martín su hijo juró cinquenta cabras que son cinco vacas.

Alonso López Herrador juró doze bueyes seys vacas quatro vacas dos yegua que son doze vacas.

Cristóval de Serrato juró nueve bueyes quatro vacas una yegua son nueve vacas y media.

$/ /{ }_{402 r}$ Juan de Orellana el moço juró su padre tres bueyes una yegua son dos vacas y media. 
Juan Hurtado juró siete bueyes que son tres vacas y media una yegua son $\mathrm{IVm}$ quatro vacas y media.

Francisco López Herrador juró cinco bueyes dos vacas y media.

IIm

Mateo de Angulo juró quinze bueyes que son siete vacas y media tres yeXVIII guas e sesenta e cinco ovejas son diez e ocho vacas.

Luys de Auñón clérigo quinze bueyes VII vacas y media.

VIIm

Juan de Umanes el moço juró dos bueyes dos yeguas son tres vacas.

III

Juan López de Angulo juró dos bueyes una vaca.

Pedro García Terrona juró una vaca e quatro bueyes son tres vacas.

Alonso de Alcántara el viejo juró que tiene catorze vacas e diez bueyes e tres yeguas e veynte cochinos son veynte e quatro vacas.

Bartolomé de Alcántara juró seys bueyes dos yeguas treze vacas son todas e XVIII vacas.

Ruy García Herrador juró seys bueyes una yegua son quatro vacas.

XVIII

La bibda de Juan Sánchez juró que tiene dos vacas e dos bueyes son tres.

Francisco de Oca m

Francisco López Barbero juró ocho bueyes veynte vacas tres yeguas cinquenta puercos son todas treynta e tres vacas.

Cristóval de Castro juró quatro vacas e tres bueyes una yegua.

Martín Caro juró dos bueyes una vaca.

Martín Fernández del Lunar juró cinco vacas tres bueyes vaca y media una yegua e diez e nueve puercos dos vacas son nueve vacas y media.

Francisco Ximénez yerno de Andrés de Oca juró una yegua.

$/ /_{402 \mathrm{v}}$ Juan Amigo yerno de la Azuaga juró tres bueyes.

La bivda de Muñoz Fernández de la Fuenllana

Diego Lobillo ocho bueyes e veynte e quatro vacas e dos yeguas son todas treynta vacas.

Juan Gómez Texedor juró diez vacas doze bueyes dos yeguas sesenta e cinco puercos son veynte e quatro vacas y media.

Diego Fernández de Araçena un buey y una vaca.

Pedro Díaz de Teba juró quatro bueyes tres vacas son todas cinco vacas.

Juan Gutiérrez de Hernán Pérez juró seys vacas.

Martín Ruyz hijo de Bartolomé Ruyz.

Diego González de Jarava juró una vaca dos bueyes.

Pedro Romero juró un buey.

Pedro Martín Destrada juró nueve bueyes que son quatro vacas y media dos yeguas que son todas seys vacas y media.

Cristóval Destrada juró tres vacas e tres bueyes vaca y media que son quatro vacas y media.

Antón González Ruvio juró dos bueyes una vaca. 
El bachiller Salvador de Jaraba juró Miguel Sánchez Rabadán que tiene ciento e siete vacas e veynte e dos herales y treynta bueys domados y seis novillos nuevos y tres yeguas e ciento e ochenta ovejas que son CLXX vacas.

Pero Martín de Castro juró que tiene dos bueyes que son una vaca.

Alonso Martín Valverde juró diez vacas con dos bueyes tres yeguas son treze vacas.

Alonso Martín su hijo juró cinco vacas e dos bueyes.

Juan Cerrato juró ocho bueyes que son quatro vacas e nueve vacas e una yegua e cinquenta e quatro cochinos son todas (XIX) vacas y media.

La bivda de Pedro Martín de Castro

Rodrigo Moreno juró un buey.

Alonso Garrido juró un buey media vaca.

Juan Fernández Mateos juró que tiene ciento e ocho vacas con herales e seys bueyes que son tres vacas e una yegua son todas ciento e doze vacas con las del lomo del grallo.

Cristóval de Vilches juró seys bueyes que son tres vacas.

Cristoval Ximenez de Ostma.

$/ /{ }_{403 v}$ Pedro Ximénez de Vargas juró quatro bueyes que son dos vacas.

La bivda de Diego Martín de Molina juró dos vacas y media son tres bueyes. $\operatorname{IIm}[\mathrm{sic}]$ Asensio Román juró quatro bueyes que son dos vacas.

Bartolomé Sánchez de Marchena juró quarenta cabras que son quatro vacas.

Alonso García Bravo juró quatro bueyes son dos vacas.

Juan Lobo hijo de Diego Martín juró cinco bueyes dos vacas e media e una yegua que son tres vacas.

Bartolomé Fernández Portugués juró ciento e ochenta cabras que son diez e ocho vacas otras dos vacas que son veynte vacas.

Miguel Martín Açofeyfo.

Alonso Gareía Hermosín.

Pedro Fernández Morillas juró un buey y media vaca.

Juan de Orellana alvañil juró dos vacas seys bueyes tres vacas una yegua e honze puercos una vaca que son siete vacas.

Diego González Orellana juró un buey.

$/ /{ }_{404 r}$ Diego Ruyz de Porras juró una yegua.

Miguel de Molina juró siete vacas e un buey una vaca son.

Elvira Fernández la de Baytos juró por Baytos siete bueyes son tres vacas y media.

Antón González de Mayrena el moço tres vacas y media. 
Alonso Ramírez juró dos bueyes e una vaca e trezientas e cinquenta cabras son treyntya e seys vacas.

Sancho Moreno juró cinco yeguas dos bueyes son seys vacas.

Diego del Castillo juró treynta e cinco vacas.

XXXV

Antón de Medina hermano de la de Sánchez Moreno juró Sánchez Moreno que tiene dos vacas.

La bivda de Andrés Martín Tresquilados juró su hijo seys bueyes que son tres vacas.

Miguel Martín Carpintero juró dos bueyes.

Francisco Sánchez criado de Orejón juró quatro vacas e dos bueyes e una yegua son seys vacas.

Juan Pérez hijo de Cristóval Feo juró que tiene dos bueyes que es una vaca.

Alonso Rodríguez de Vaena juró tres bueyes e una vaca son dos vacas y media.

Rodrigo Alonso yerno de Alexo García juró quatro bueyes dos vacas una yegua son tres.

Gil Ruyz de Porras juró su muger y tiene seys vacas e tres bueyes son siete vacas y media.

Juan Bravo juró tres vacas dos bueyes unas son quatro vacas.

Cristóval Gutiérrez de Porras juró que tiene una vaca.

Francisco Martín yerno de Martín García juró diez vacas y una yegua.

Garçi Fernández yerno de Bartolomé Ruyz juró tres bueyes e una yegua son dos vacas y media.

Antón García de Holvera tiene tres bueyes vaca y media.

$/ /{ }_{405 r}$ Pedro González Capitas juró tres vacas seys bueyes son tres vacas son seys vacas y media.

Elvira Díaz la Ginovesa juró Hernán Martín su hijo que tiene dos bueyes es vaca y media.

\section{Diego Muñoz.} dos yeguas diez vacas que son catorze vacas y media.

Juan de Morón yerno de la de Juan de Luna quatro bueyes e dos yeguas son tres vacas.

Martín Fernández de Alcántara juró que tiene quatro bueyes e tres vacas que son cinco vacas.

Cristóval Martín Murillo juró dos bueyes una vaca.

Martin Sánehez Amigo.

Martín García Albardero juró dos bueyes.

\section{I}


Antón López Villalón juró Pedro García de Coca que tiene seys bueyes dozientas e sesenta cabras una yegua son treynta e una vaca.

Sancho García Lobato un buey juró.

Alonso Ximénez yerno de Juan de Angulo juró çinco bueyes dos vacas y media una yegua una vaca es vaca y media.

Juan Martín Bernal.

$/{ }_{405 v}$ Leonor Sánchez la monja juró Francisco de Umanes que tiene tres bueyes que es vaca y media.

Juan Fernández Villalón cinquenta e tres vacas e veynte e dos bueyes e cinco yeguas montan todas sesenta e nueve vacas.

Mayor Sánchez bivda juró tres bueyes e dos vacas son tres vacas y media.

Alonso de Valbuena juró sesenta e siete vacas dozientos puercos XLII bueyes e una yegua son noventa e seis vacas y media.

Diego Fernández el viejo juró que tiene diez vacas cinco cabras media vaca.

Ynés Gutiérrez la Catalana juró ciento e diez e siete vacas e treynta e quatro bueyes que son diez e siete vacas e tres yeguas e ciento e veynte ovejas que son doze vacas çiento e quarenta e nueve vacas.

Lucía Bernal juró tres bueyes e seis vacas son siete vacas y media.

VIIm

Pedro García Parejo juró diez e nueve vacas ocho bueyes quatro vacas dos yeguas que son veynte e cinco vacas.

Juan Despinal el moço juró Antón Romero el moço que tiene cinquenta e siete vacas y media e XXVIII bueyes son XIIII bacas una yegua XL ovejas e cinquenta e cinco puercos son todos ochenta e tres vacas y media.

Francisco Fernández yerno de Juan de Umanes IIIL bacas III bueys son IIIIm. Antón Martín de Herrera juró quatro bueyes que son dos vacas. // ${ }_{406 r}$ Martín Fernández Morán juró que tiene seteçientas cabras que son setenta vacas.

La bivda de Juan Moreno juró su yerno dos bueyes.

El bachiller Francisco de Umanes juró veynte cabras. gua son honze vacas.

Juan González Nieto juró seys bueyes e dos vacas e dos yeguas que son siete vacas.

Juan de Morón yerno de Cristóval de Galán juró que tiene catorze bueyes dos vacas que son nueve vacas e una yegua que son diez vacas.

La Catalana de Bartolomé Martín Vaquero juró LXXI vacas e treze bueyes e una yegua e cinco ovejas son por todas setenta e nueve vacas.

Juan Martín de Juan Myguel juró que tiene quatro bueyes que son dos vacas.

Marina Cortés juró que tiene dos vacas.

Nieto su hermano un buey media vaca.

LXX

I

Asensio González.

Cristóval de la Viga juró tres bueyes vaya y media. 
Alonso López Arenillas juró que tiene quatro bueyes e dos vacas que son IIII quatro vacas.

Juan de Angulo juró ocho bueyes que son quatro vacas e una yegua son çinco vacas.

$/ /{ }_{406 \mathrm{v}}$ Alonso Muñoz juró un buey.

Juan Fernández Mexines juró quatro bueyes e dos yeguas son quatro vacas.

Cristóval García de Cote juró siete bueyes que son tres vacas y media quatro vacas una yegua que son ocho vacas y media.

La bivda de Juan de Marchena juró treynta e nueve cabras que son quatro vacas.

Alonso Martín Bonitón juró honze bueyes que son çinco vacas y media dos vacas e dos yeguas que son todas nueve vacas y media.

Pedro González Nyeto juró cinco bueyes dos vacas y media e una yegua son tres vacas y media.

Pedro Mateos de Málaga juró XV vacas ocho bueyes tres yeguas son veynte e dos vacas.

La bivda de Juan Nuñez juró diez veynte e un bueyes son diez vacas e media e treynta e ocho vacas e dos yeguas e çiento e veynte ovejas son doze vacas son por todas sesenta e dos vacas y media.

Juana Martín la Polida juró un buey media vaca más quatro vacas y media son cinco vacas.

Antón de Morillas juró que tiene ocho bueyes e una vaca e una yegua VI vacas.

/ ${ }_{407 \mathrm{r}}$ Cristóval Gallego juró diez e nueve vacas e seis bueyes que son tres vacas e dos yeguas dos vacas que son veynte e quatro vacas.

Juan Gómez Terrona juró veynte e siete vacas tres bueyes dos yeguas e seys puercos e trezientas e veynte cabras son todas sesenta e tres vacas.

Bartolomé de Colástica juró diez e siete vacas diez bueyes cinco vacas dos yeguas dos vacas setenta e cinco ovejas siete vacas y media que son treynta e un vacas y media.

Miguel Sánchez Rabadán juró que tiene quatro bueyes e una yegua son tres vacas.

Francisco de Coria juró setenta e seys vacas e veynte e tres bueyes honze vacas y media tres yeguas que son ochenta vacas y media.

Cristóval Galán XLII bueyes son XXI vacas XVIII bacas cinco yeguas que son todas XLIIII vacas.

Juan López de Auñón juró que tiene quatro bueyes dos vacas e una yegua son tres vacas.

Francisco Bohórquez juró Francisco de Coria que tiene setenta e siete vacas nueve bueyes una yegua son ochenta e dos vacas y media.

Martín Gutiérrez Amo juró siete bueyes e dos vacas una yegua son seys vacas y media.

Pedro Villegas juró que tiene tres bueyes que es vaca y media.

LXXXm

fuan de Moron yerno de Cristoval Galan. 
$/ /{ }_{407 v}$ Pedro Gutiérrez de Hernán Pérez juró que tiene catorze bueyes que son siete vacas e trezientas e cinquenta cabras son XXXV vacas dos yeguas son XLIIII vacas y mas XVII vacas.

Martín Gutiérrez su hermano juró que tiene un buey e una yegua que es una vaca e media.

Andrés Martín Ruvio juró dos vaeas e veynte e dos bueyes que son honze XIIII vacas tres yeguas son catorze vacas.

Pedro Gutiérrez Zorro juró seys bueyes tres vacas tres vacas una yegua siete vacas son.

Hernán García Palomo juró que tiene seys bueyes tres vacas.

XLIIII

XVII

$\operatorname{Im}$

VII

Pedro Fernández Nieto juró diez e nueve vacas e siete novillos que son siete vacas e ocho bueyes que son todos treynta vacas.

Francisco Fernández de la Plaça juró ocho vacas e un buey.

La bivda de Alonso Ruyz de los viejos.

Rodrigo de Vilches juró seys bueyes que son tres vacas.

$/ /{ }_{408 \mathrm{r}}$ La Bivda de Diego Gil juró quatro vacas dos bueyes una vaca.

Francisco de Angulo IIII bueyes que son dos vacas.

La bivda de Antón Fernández de la Fuenllana un buey que es media vaca.

Miguel Sánchez de Bejer juró que tiene quatro bueyes que son dos vacas.

Pedro Ruyz de Porras juró ocho bueyes dos vacas dos yeguas son ocho vacas.

Cristóval Sánchez de Coca juró dos bueyes tres vacas ochenta cabras son doze vacas.

Antón Fernández Serrano juró tres bueyes.

Pedro Sánchez Orejón juró tres vacas e quatro bueyes son cinco vacas.

Garci Fernández Carpintero juró dos bueyes una vaca.

Elvira Ruyz la Ruvia.

Bartolomé García de Carmona juró nueve vacas çinco bueyes dos vacas y media una yegua e veynte puercos dos vacas cinco ovejas cinco vacas son diez e nueve vacas y media.

Alonso Díaz Benjumea juró siete bueyes e çinco nueve vacas dos yeguas son catorze vacas y media.

$/{ }_{408 v}$ Francisco Díaz Benjumea juró nueve bueyes quatro vacas y media siete vacas dos yeguas que son treze vacas y media.

Martín Gil juró çinco vacas e tres bueyes una vaca y media una yegua que son siete vacas y media.

ftan Ximón.

Pedro Fernández Xabonero juró dos bueyes que son una vaca.

Antón Martín de Marchenilla juró dos bueyes que es una vaca. 
Pedro García Herrador juró ocho vacas syete bueyes tres vacas y media tres

$\mathrm{XXm}$ yeguas que son catorze vacas y media sesenta puercos seys vacas.

Juan Blázquez de Coca juró treze vacas doze bueyes seys vacas tres yeguas son veynte e dos vacas.

Juan de Angulo juró de que fue seys bueyes tres vacas dos yeguas son cinco vacas.

$/ /{ }_{409 \mathrm{r}}$ Juan Catalán juró siete bueyes son tres vacas y media e treynta e çinco puercos que son tres y media son todas syete vacas.

Martín González juró un buey e çinco puercos es media vaca.

Cristóval de Castro juró que tiene tres vacas y un buey que son tres vacas y media.

Antón Martín de Palma juró un buey media vaca.

Francisco Sánchez de Bonilla juró que tiene tres vacas e çinco bueyes que son dos vacas y media e çinco ovejas que son todas seys vacas dos yeguas.

Martín Fernández de los viejos juró tres vacas e siete bueyes tres vacas y media una yegua çiento e diez puercos honze vacas son diez e ocho vacas y media.

Pedro Fernández de Villalta tiene XIIII bueyes son VII vacas XXVIII vacas y yeguas XXX ovejas.

Marcos López juró doze vacas e nueve bueyes que son quatro vacas y media dos yeguas son todas XVIII vacas y media.

Juan Blázquez de Coca el viejo juró quinze vacas diez bueyes çinco vacas dos yeguas que son veynte e dos vacas.

Martín Lobo.

Juan Sánchez Trapero juró cinquenta e un buey son XXV vacas y media e veynte e cinco vacas tres yeguas son cinquenta e tres vacas y media.

$/ /{ }_{409 \mathrm{v}}$ Francisco Vázquez escribano público juró noventa nueve cabras que son diez vacas.

La bivda de Juan López Boticario.

Juan de Vargas juró veynte vacas cinco bueyes son veynte e dos vacas y media.

Diego de Madrid.

La bivda de Diego Fernández.

Diego Gutiérrez juró un buey que es una vaca.

Diego de Vaena juró diez seys vacas treze bueyes seys vacas y media son veynte e tres vacas y media.

Mareos Fernández.

fuan Lopez

Calle de Martin

Bartolomé González de Mayrena juró que tiene nueve bueyes e diez vacas que son catorze vacas e media.

Juan Lobo de Holvera juró que tiene siete bueyes suyos e de su hijo e tres vacas y seys vacas y media.

// ${ }_{410 \mathrm{r}}$ Juan Romero juró çinco vacas dos bueyes una vaca una yegua son siete vacas.
LIIIm

XXII 
Antón Romero juró cinquenta e ocho vacas y media e veynte e syete bueyes son treze vacas y media e sesenta ovejas son seys vacas e quarenta e oeho puercos e dos yeguas son todas ęiento e treynta e ocho vaeas ochenta e quatro vacas.

Juan Fernández Despinal.

Pedro López de Reyna juró ocho vacas honze bueyes que son cinco vacas y media dos yeguas son quinze vacas y media.

Diego Çerrato juró ocho vacas çinco bueyes diez ovejas una yegua son doze vacas y media.

Antón Ximénez de la Morena juró que tiene dos bueyes que son una vaca.

Pedro Fernández Galindo juró LX puercos e una yegua son.

Juan Portillo un bueys diez e ocho vacas que son todas veynte vacas.

Leonor López la Morzilla juró su hijo el casado que tiene seys bueyes e una yegua.

Diego Fernández Rabadán juró quatro bueyes dos vacas e çiento e veynte e çinco cabras que son catorze vacas y media.

$/{ }_{410 \mathrm{v}}$ Pedro González Chamorro juró noventa e cinco cabras que son nueve vacas y media dos bueyes una vaca que son diez vacas y media.

Alonso Romero juró quatro bueyes dos vacas una yegua son tres vacas.

Alvar González juró seys bueyes e dos yeguas son cinco vacas.

Alonso Navarro juró tres bueyes e tres vacas son quatro vacas y media.

Juan Romero juró dos bueyes e una vaca son dos vacas.

Asensio González Ximénez yerno de la de Alonso Gutiérrez Villalón juro que tiene dos bueyes que es una vaca.

Antón Romero alguazil juró que tiene dos bueyes e dos yeguas son tres vacas.

Cristóval de Angulo juró que tiene ciento e sesenta vacas XVIII bueyes que son IX e LXX puercos quatro yeguas monta todo dozientas e treynta vacas. Alonso Fernández de Castro juró tres bueyes.

Catalina Vázquez que es bivda tiene dos bueyes una vaca.

Alonso Ximénez yerno de Juan Martín juró una yegua e un buey que es vaca y media.

$/{ }_{411 r}$ Lázaro García de Arenas juró ciento e sesenta e seys vacas ovejas son diez e seys vacas mas e dozientos e treynta e syete puercos veynte e tres vacas y media una yegua ocho bueyes quatro vacas cien carneros que son diez vacas son cinquenta e cinco vacas.

Juan de Angulo hijo de Hernán Muñoz juró seys bueyes que son tres vacas e honze cochinos.

Antón López de Guerra juró seys bueyes tres vacas.

Gristoval de Moron.

Juan Gallego juró dos bueyes una vaca. 
Calle de Juana la Prieta

Calle del Barrio de Santa María

\section{(1)}

Miguel Ximénez yerno de Aguilera juró çinco bueyes dos vacas diez puercos son cinco vacas y media.

Juan Calero juró dos bueyes que son una vaca.

$\mathrm{Vm}$

Pedro de Teba yerno de Diego Gutierrez.

Diego Fernández Araçena juró seys bueyes tres vacas dos yeguas son cinco vacas.

Andrés Estevan juró dos bueyes una vaca.

$/ /{ }_{411 v}$ Antón Martín de Castro juró tres bueyes vaca y media quatro vacas dozientas e treynta cabras son veynte e tres vacas son todas veynte e nueve vacas y media con una yegua.

Martín Fernández de Castro.

Hernán González de los viejos juró siete bueyes una yegua treze puercos son cinco vacas y media.

Ruyz González yerno de Carrizo juró dos bueyes una vaca.

Ruyz Ximénez juró seys bueyes e ciento e ochenta cabras que son veynte e una vacas.

Alonso de Morón el viejo juró nueve bueyes quatro vacas y media una yegua.

Pedro Ximénez Parra juró veynte vacas ocho bueyes dos yeguas e quatro ovejas son veynte e seys vacas y media.

Hernán Estevan que mora en las casas de Antón de Coria juró que tiene un buey media vaca.

Juan Díaz yerno de Juan Estevan juró çinco vacas dos bueyes una yegua son siete vacas.

Francisco Navarro juró quatro bueyes dos vacas.

Juan de Holvera yerno de Crespo juró tres bueyes.

Bartolomé Lobillo juró çinco vacas e syete bueyes e una yegua son nueve vacas e media.

Pedro Dientes juró que tiene çinco vacas e media.

$/ /{ }_{412 \mathrm{r}}$ Hernán García Çalamea juró seys bueyes e seys vacas e çien puercos e una yegua que son todas veynte vacas.

Estevan Ginete juró cinco bueyes una yegua e ochenta puercos son honze vacas y media.

Calle de

Bartolome de

Umanes
Juan de Holvera juró dos vacas dos bueyes e quinze cochinos son quatro vacas y media.

Pedro González Amo juró su hijo Juan de Morón que tiene dos bueyes una vaca.

Bernal García juró tres bueyes e una vaca e una yegua son tres vacas y media.

Francisco de Angulo juró ocho bueyes que son quatro vacas.

La bivda de Dientes declaró que tiene quatro bueyes que son dos vacas e una yegua III vacas.

Francisco Hortiz juró quatro vacas y dos bueyes una yegua son seys vacas.

La Maguilla de los (...) dos bueyes que son I vaca.
$\mathrm{Vm}$

XXXVIm 
Juan de Morón juró una yunta de bueyes una vaca.

$/{ }_{412 \mathrm{v}}$ Bartolomé de Umanes juró quinze bueyes son siete vacas y media e ciento e treynta e dos vacas DII puercos dos yeguas son todo dozientas e honze vacas y media.

Antón de Molina juró quatro bueyes que son dos vacas.

Rodrigo de Morillas yerno del alcalde tyene seys bueyes que son tres vacas.

Antón López Maldonado juró un buey e una vaca.

Hernán Martín de Gandul juró que tiene cinco bueyes que son.

Alonso de Alcántara juró quatro vacas seys bueyes tres vacas son siete vacas. Juan Fernández de Vilches juró que tiene dos bueyes.

Hernán García Baytos juró tres bueyes dos vacas e dozientas e veynte cabras son veynte e cinco vacas y media.

Juan Nieto yerno de Molina juró tres bueyes vaca y media.

Miguel Gómez juró tres bueyes y una vaca son.

Juan Fernández de Morillas XC puercos XC ovejas VIII bueys II yeguas son XXIIII vacas.

Pedro Fernández yerno Açofeyfo juró seys vacas.

$/ /{ }_{413 \mathrm{r}}$ Hernán Martín Caçorla juró nueve bueyes quatro vacas y media dos yeguas dos vacas que son seys vacas y media.

Calle de Cristoval Crespo

Cristóval Martín Crespo juró veynte e nueve vacas ocho bueyes son treynta e tres vacas.

Antón Ximenes Ginete juró un buey.

Martín García Crespo juró que tiene dos bueyes ques una vaca.

Alonso García de Holvera juró dos bueyes.

Bartolomé Párraga juró que tiene tres bueyes que es vaca y media.

Pedro de Morón el moço tyene un buey que es media vaca.

Hernán García Saldaña juró que tiene cinquenta cabras e una vaca son seys vacas.

Cristóval Márquez juró que tiene dos bueyes e una yegua.

Francisco Guerrero juró dos buetes que es una vaca.

\section{Garȩi González eseribano públieo.}

Martín Villalón declaró Juan (...) que tiene diez e nueve bueyes que son IX vacas y media e veynte e çinco vacas que son XXXIII y media.

Pedro Gutiérrez de Sancho Ximénez XLV cabras que son IIII vacas y media.

Calle de la Plaça de Sennor Sant Miguel
$/ /{ }_{413 v}$ Pedro González Orellana juró mile e trezeitnas e quarenta cabras de todas e cinquenta e dos bueyes e diez e nueve vacas e tres yeguas que son todas çiento e ochenta e dos vacas.

Alonso de Morón su yerno juró quinze bueyes e una yegua son ocho vacas y media.

Hernán Martín de Angulo juró ciento e tres quinze vacas nueve bueyes e quarenta ovejas son çiento e veynte e tres vacas y media.
XIIIm

IIII

CLXXXI

VIIIm

CXXIIIm 
El Licenciado Luna juró honze bueyes son cinco vacas y media e quatro XIIIm vacas e quatro yeguas son treze vacas y media.

Sebastián de Trugillo juró quatro vacas e tres bueyes e una yegua son seys vacas y media.

Diego de Morillas tyene ciento y diez y syete cabras que son.

VIm

Francisco Núñez juró ocho vacas e seys bueyes tres bueyes e çien cabras diez vacas son XXI.

Francisco Martín que bive a la puerta de Holvera juró dos vacas y media.

Juan Álvarez a la peña el Milano juró un buey media vaca.

Los menores de Pedro García Amigo juró honze bueyes que son cinco vacas e media.

El menor de Pedro Ruyz juró Juan Gómez de Porras que tiene dos bueyes que es una vaca.

La menor de Alonso de Umanes juró Pedro González treze bueyes que son seys vacas y media tres vacas que son nueve vacas y media.

Los menores Nieto de la Chamorra tutor Pedro Santos un buey y diez cabras que son I vaca e media.

La tutela de la que es tutor Francisco Sánchez Trugillo juro que tiene ocho bueyes que son quatro vacas.

Tutela de la menor de Juan Catalán tutor Hernando de Valbuena II bueyes que son una vaca.

Tutela de los menores de Juan de Umanes juró el tutor que tiene cinco bueyes dos vacas y media.

Tutela del menor de Benviesca juró dos bueyes una vaca.

$/{ }_{414 \mathrm{v}}$ Tutela que tiene Juan Cerrato (...).

Tutela de los hijos de Martin Vençón con tutor Juan Despinal IIII bueyes.

Tutela de la menor de Juana de Aguilar juró el tutor que tiene dos bueyes.

Tutela de la menor Despinal tutor Alonso de Balbuena juró quatro bueyes son dos vacas.

Tutela de que es tutor Juan Blázquez de Coca moço un buey.

Tutela de los menores de Juan Díaz juró Francisco Díaz tutor que tienen dos bueyes que es una vaca.

Tutela de los menores de Luys de Vilches juró Cristóval de Vilches que tiene dos bueyes una vaca.

Tutela de los hijos de Antón Martín de Guerra juró Miguel Ximénez tres bueyes.

Tutela de Pedro Nieto es tutor Pedro Gómez juró que tiene tres bueyes. 
$/ /{ }_{415 \mathrm{r}}$ En la villa de Morón, dos días del mes de octubre de mile e quinientos e treinta e dos años, estando juntos el noble señor Juan Fernández de las Casas, alcaide e corregidor desa villa, e los honrados Juan Fernández de Morillas, alcalde ordinario, e Juan Lobo de Olvera e Alonso de Alcántara, regidores, e Pedro Mateos, jurado, en presencia de mí, Juan de Couos, escribano público. Juan Gutiérrez de Balbuena, escribano público e del cabildo de la villa del Arahal, hizo muestra del libro y padrón, el qual dixo ser del ganado que se empadronó en la dicha villa del Arahal, de los vecinos della, para pagar la yerva deste presente año, el qual fue visto, e mentando las reses que por el dicho libro tenía escriptas, se hallaron syete mile e novecientas e veynte e una vacas, e asimismo fue mentado e viso el padrón desa dicha villa de Morón, por el qual paresció aver en él cinco mile e secenta vacas, que son las unas y las otras doze mil e noveçientas e ochenta y una vacas. XIIU DCCCC LXXXI.

\begin{abstract}
A los quales se le repartieron los cinquenta mille maravedís questa dicha villa e la del Arahal son obligadas a pagar cada dicho año de la dicha yerva, e sobre cada cabeça a quatro maravedís, y sobran myle e noveçienconçejos, por manera que cabe a la dicha villa de Morón de pecha veynte myle e dozientos y quarenta maravedís, y al conçejo del Arahal treynta e un mile seysçientos e ochenta e quatro maravedís. E asy se hizo la dicha quantía estando presente en ella los dichos sus alcaldes e oficiales e el dicho Juan Gutiérrez de Valbuena, escribano público susodicho//.
\end{abstract}

XXXIU DCLXXXIII tos e treinta e quatro maravedís para las cosas de ambos XXU CXL

Juan Gutiérrez, escrivano público.

\title{
BIBLIOGRAFÍA
}

Andreolli, Bruno (2001-2002), “L'uso del bosco e degli incolti”, Pinto, Giuliano, Poni, Carlo, Tucci, Ugo (A cura di), Storia dell'agricoltura italiana. Il medioevo e l'età moderna, Firenze: Accademia dei Georgofili, pp. 123-144.

Argente Del Castillo Ocaña, Carmen (1991), La ganadería medieval andaluza. Siglos XIII-XVI (reinos de Jaén y Córdoba), 2 vols., Jaén: Diputación.

Cabrera Muñoz, Emilio (2002), "El bosque, el monte y su aprovechamiento en la España del sur durante la Baja Edad Media", Pérez-Embid, Javier (ed.), Andalucía Medieval. Actas I Jornadas de Historia Rural y Medio Ambiente. (Almonte, 23-25 mayo 2000), Huelva: Universidad, pp. 249-272.

Carmona Ruiz, María Antonia (1995), La ganadería en el Reino de Sevilla durante la Baja Edad Media. Sevilla.

Carmona Ruiz, María Antonia (1996), "La actividad ganadera en la Banda Morisca", en Actas de las II Jornadas de Temas Moronenses. La Banda Morisca durante los siglos XIII, XIV y XV (17 al 20 de octubre de 1994). Sevilla, pp. 157-173.

Carmona Ruiz, María Antonia (1997a), "La ganadería en Carmona durante la Baja Edad Media”, en Archivo Hispalense: Revista histórica, literaria y artística, 
Tomo 80, $\mathrm{n}^{\mathrm{o}}$ 243-245, (Ejemplar dedicado a: I Congreso de Historia de Carmona: Edad Media. Actas), pp. 283-326.

Carmona Ruiz, María Antonia (1997b), "Los aprovechamientos interconcejiles de Tierras comunales: la Hermandad de Pastos entre Marchena, Morón, Arahal y la Puebla de Cazalla de 1501", en Actas de las II Jornadas Sobre Historia de Marchena. Marchena Bajo los Ponce de León. Marchena, Ayuntamiento de Marchena, pp. 123-140.

Carmona Ruiz, María Antonia (2000a), "El aprovechamiento de la Algaida de Cote (Bosque de San Pablo, Montellano) ss. XIII-XVI", en Apuntes 2: Apuntes y Documentos para una Historia de Osuna, no. 3, pp. 29-58.

Carmona Ruiz, María Antonia (2000b), "Las relaciones agricultura-ganadería en la Reglamentación Concejil Tardomedieval. Las ordenanzas de El Arahal”, en La Andalucía medieval: actas I Jornadas de Historia Rural y Medio Ambiente. Almonte, pp. 345-354.

Carmona Ruiz, María Antonia (2001), "Volumen y distribución de la cabaña ganadera en el Reino de Sevilla: Finales del XV-Principios del XVI", en Historia. Instituciones. Documentos, ${ }^{\circ}$ 28, pp. 31-89.

Carmona Ruiz, María Antonia (2009), "Ganadería y frontera: los aprovechamientos pastoriles en la frontera entre los reinos de Sevilla y Granada. Siglos XIII al XV", En la España medieval, no 32, pp. 249-272.

Carmona Ruiz, María Antonia (2011), "La villa de Arahal en el contexto de las actividades ganaderas en la "Banda Morisca", en Archivo Hispalense, t. 94, no. 285-287, pp. 17-49.

Carmona Ruiz, María Antonia (2014), "Las actividades pastoriles en Jerez de la Frontera: siglos XIII-XIV”. 750 aniversario de la incorporación de Jerez a la Corona de Castilla: 1264-2014, coord. por Manuel Antonio Barea Rodríguez, Manuel Romero Bejarano; José Sánchez Herrero (dir.), Manuel González Jiménez (dir.), pp. 195-219.

Clemente Ramos, Julián (ed.) (2001), El medio natural en la España Medieval. Actas del I Congreso sobre ecohistoria e Historia Medieval, Cáceres: Universidad.

Devís Márquez, Federico (1997), “Señorío y control de pasto en Andalucía: estructura y valor de la renta señorial en Zahara de la Sierra (1484-1556)", Loring García, María Isabel (ed.), Historia social, pensamiento historiográfico y Edad Media. Homenaje al Prof. Abilio Barbero de Aguilera, Madrid: Ediciones del Orto, pp. 475-494.

García Fernández, Manuel (2005), La Campiña Sevillana y la Frontera de Granada (siglos XIII-XV). Estudios sobre poblaciones de la Banda Morisca. Sevilla.

García Fernández, Manuel (2011), "El Arahal y la "Banda Morisca. La frontera compartida (siglos XIII- XV)”, en Archivo Hispalense, t. 94, n. 285-287, pp. 51-67.

González Jiménez, Manuel (1987), "Morón de la Frontera a comienzos de s. XV", en Anuario de estudios medievales. Barcelona, CSIC, n. 17, pp. 401-422. 
González Jiménez, Manuel. y García Fernández, Manuel (ed.) (1992), Actas capitulares de Morón de la Frontera (1402-1426). Diputación Prov. de Sevilla.

González Jiménez, Manuel (1996), “La Banda Morisca en el Siglo XIII: el nacimiento de una frontera", pp. 13-23, en Actas de las II Jornadas de Temas Moronenses. La Banda Morisca durante los siglos XIII, XIV y XV. Sevilla.

Martín Gutiérrez, Emilio (2015), Paisajes, ganadería y medio ambiente en las comarcas gaditanas. Siglos XIII al XVI, Cádiz-Extremadura: Universidad.

Martín Humanes, José María (2015), "La aldea de Arahal en el tránsito a la modernidad (ss. XV-XVI)", en Archivo hispalense: Revista histórica, literaria y artística, t. 98, n. 297-299, 2015, pp. 279-307.

Monsalvo Antón, José María (2010), Comunalismo concejil abulense. Paisajes agrarios, conflictos y percepciones del espacio rural en la Tierra de Ávila y otros concejos medievales, Ávila: Diputación.

Villalonga Serrano, José Luis (2007), Hacer un muy buen pueblo. Del campo de Matrera a Villamartín: análisis de un proceso repoblador en la banda morisca del Reino de Sevilla (1256-1503). Universidad de Sevilla.

Fecha de recepción del artículo: 13 de noviembre de 2016

Fecha de aceptación y versión final: 18 de enero de 2017 
